\title{
Mortality and morbidity among the working population of anthophyllite asbestos miners in Finland
}

\author{
L. O. MEURMAN, R. KIVILUOTO, and M. HAKAMA \\ Department of Pathology, University Central Hospital of Kuopio, Kuopio, and Finnish \\ Cancer Registry, Helsinki, Finland
}

\begin{abstract}
Meurman, L. O., Kiviluoto, R., and Hakama, M. (1974). British Journal of Industrial Medicine, 31, 105-112. Mortality and morbidity among the working population of anthophyllite asbestos miners in Finland. A study has been made in Finland of the effects of anthophyllite asbestos on mortality and morbidity of 1092 asbestos workers first employed at two mines between 1936 and $1969 ; 95 \%$ of workers were traced, 248 of whom had died. A similar number of agesex-matched controls was selected from a township $60 \mathrm{~km}$ from the mines. The causes of death included an excess due to lung cancer and asbestosis, but cancers of the digestive system occurred in equal frequency, and neither the cases nor controls had any confirmed mesotheliomas. Assuming a multiplicative effect of asbestos and smoking, the relative risk of lung cancer was 17 for an asbestos worker who smokes in terms of a non-exposed nonsmoker. The corresponding figures were 12 for a smoker without asbestos exposure and 1.4 for an asbestos worker who did not smoke. More heavy smokers were found among the asbestos workers than among the controls. A threefold excess of dyspnoea and a twofold excess of cough were recorded for the asbestos workers compared with the controls after adjustment for smoking.
\end{abstract}

It has been demonstrated that asbestos dust results in harmful effects upon man's health in three different ways: lung cancer, asbestosis, and diffuse pleural or peritoneal mesothelioma (Wright, 1969). Some evidence also exists for increased mortality from other malignancies, particularly cancer of the digestive organs (Mancuso and Coulter, 1963; Selikoff, Churg, and Hammond, 1964; Enterline, 1965). Considerable interest has been focused upon the possible difference in health hazards resulting from various kinds of asbestos. It is known that asbestos minerals obtained from various sources in the world have a wide range of chemical and physical differences (Timbrell, 1970) but it is common to mix various types of asbestos for industrial purposes (Newhouse, 1970). Studies of exposure to only one type of asbestos can be made in populations working as near as possible to the source of production, i.e., the mines or mills.

In North Savo, in Finland, asbestos mines have been worked since 1918. The Finnish type of asbestos anthophyllite, which belongs to the amphibole group of minerals, is relatively insoluble in human lungs compared to chrysotile asbestos, the commonest type in the world, which slowly dissolves within the lungs. In animal experiments, it has been demonstrated that anthophyllite induces lung fibrosis with a relatively short latent period (Holt, Mills, and Young, 1965). Anthophyllite is rather brittle and cannot be woven as can the more flexible chrysotile (Gaze, 1965). Chrysotile fibres are hollow tubes whereas anthophyllite fibres are solid (Gaze, 1965). In the main, anthophyllite is utilized as a cheap filler or as an insulation material by virtue of its 
excellent resistance to heat and chemicals, together with its high electrical insulation.

Since 1936, both mines in Finland have been owned by Suomen Mineraali Oy. One of the mines, Paakkila, is still in use, with an annual output of 10-15 000 tonne $(\mathrm{Mg})$. The mine is combined with a dry hammer asbestos mill, which crushes the broken rock into asbestos powder for various industrial applications. The other mine, Maljasalmi, has been used intermittently and has not been in operation since 1963. Its production of asbestos was small, and the main product was tremolite talc.

North Savo, in the heart of Finland, is a lakedotted area with large forests, mainly spruce and pine, and rather sparsely inhabited (11 persons $/ \mathrm{km}^{2}$ ). The nearest urban community with any industry worth mentioning is $50 \mathrm{~km}$ from the mine to the west. The thinly scattered population around the mill, mainly farmers making their living from agricultural and forest work, was fairly stable until the 1960s when gradual migration began to the neighbouring urban areas and southwest Finland.

There are three reasons for studying the effects of asbestos in Finland-the unusually high incidence of lung cancer (Doll, Muir, and Waterhouse, 1970); the high frequency of asbestos bodies in the lungs (Meurman, 1966); and the common occurrence of pleural fibrocalcific plaques, which are usually associated with asbestos exposure (Kiviluoto, 1960; Meurman, 1966; Raunio, 1966). Moreover, cigarettesmoking is and has for a long time been an unusually common habit in Finland (Pedersen et al., 1969).

The aim of the present study is to estimate the health hazards of anthophyllite asbestos and to compare them with the effects of other types of asbestos exposure investigated elsewhere.

\section{Materials and methods}

A personnel registry, in the form of salary lists of the two asbestos mines in Finland, had been maintained fairly completely by the mining company since 1936 . The entire records were placed at our disposal for research purposes, and further information concerned with the workers in the mines and the mill was kindly given by the company. The lists contained the names of the workers and their length of employment, and as a rule the types of work they had done. In some cases, the files did not contain the date of birth or even the year of birth, but the identification data and place of residence were checked with the official Finnish national population registry. The Church in Finland, as a state church, has registered the population for several hundred years. If a person migrates from one municipality to another the change is registered by both local church registrars.

From these sources and in the main from the salary lists, personal data and postal addresses were collected for all the workers in both mines who had been at work between 1 January 1936 and 1 June 1967 for periods of three months or more. Copies of the death certificates of those workers who had died were obtained from the Central Bureau of Statistics.

The expected numbers of deaths for cases of lung cancer and gastrointestinal cancer were estimated, with allowance for age, using the observed proportions of deaths due to different causes of death in Finland in 1958, which was the median year of death of the asbestos workers.

As no reliable comparative data were available for smoking habits and respiratory symptoms on a national basis, a special sample of controls was selected within the rural neighbourhood of the mines. At the same time it was thought useful to have matched controls for the deaths, as it was felt that different types of bias might invalidate comparison of the national mortality data with the data on asbestos workers. However, no overt differences were observed between these two groups.

A control group was obtained by selection from the local population registry of the township of Maaninka in North Savo, an agricultural area containing no mines nor other industrial plants. Maaninka has about 8000 inhabitants and is about $60 \mathrm{~km}$ to the northwest of the asbestos mines, and the distance to the nearest urban area is about $40 \mathrm{~km}$.

The controls were matched with asbestos workers for date of birth, sex, and date of death or with asbestos workers alive on 1 June 1967. The addresses of the living control cases were taken from the electoral lists, and the death certificates for the deceased controls were recorded from the Central Bureau of Statistics. If the living control case could not be contacted, someone corresponding most closely to the matching criteria for date of birth was chosen. If two or more control cases equally close to the date of birth of the case were found, the first to be noted was chosen. The matching was complete in all pairs, and the difference between the age of the case and the matched pair never exceeded one year.

A questionnaire was sent to each living asbestos worker and each control, together with a letter explaining the purposes of the study. This letter did not disclose that a survey of the effects of asbestos dust was in question but indicated only that it related to the problems arising from the possible effects of atmospheric pollution of any kind.

The principal questions were in two parts-whether or not the interviewee felt well, had a cough, and had dyspnoea; and a more detailed inquiry into smoking habits, including information on the duration of smoking and the number of cigarettes smoked daily. The questionnaire further inquired into the duration, quality, and intensity of any dusty work, the age at the beginning of exposure, and the period of such exposure.

The risk of different respiratory symptoms and diseases was evaluated in terms of prevalence rates and the relative risks. The rates were adjusted in accordance with smoking habits, the distribution of different smoking categories in the total controls being taken as standard.

\section{Results}

The number of asbestos mining company employees known to have been at work for a period of at least three months between 1 January 1936 and 1 July 1967 was 1092 . The number of employees with 
complete follow-up at the termination of the study on 20 May 1969 was $1041(95 \cdot 3 \%$ ) (Table 1).

\section{TABLE 1}

Number of Workers in Asbestos Mining COMPANY KNOWN TO HAVE WORKED FOR THREE MONTHS OR LONGER BETWEEN 1 JANUARY 1936 AND 1 JULY 1967, BY Follow-UP STATUS

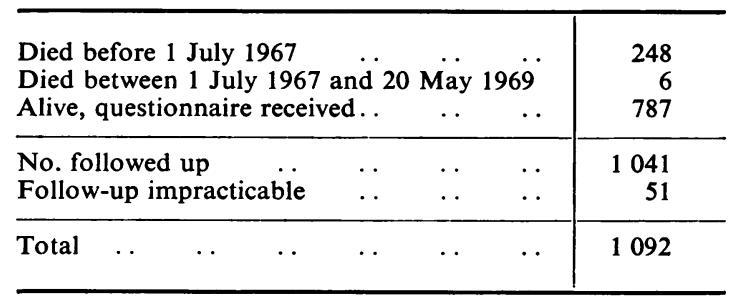

\section{Analysis of causes of death}

Of the 1092 employees, 248 were known to have died by the termination of the study. In 35 asbestos employees and 25 controls information on the causes of death was based on necropsy. Table 2 gives the number of deaths by cause among the asbestos employees and the controls. Special emphasis was laid upon deaths from asbestosis, lung cancer, cancer of the digestive organs, and mesotheliomas. No case of mesothelioma was found. Asbestosis was the primary cause of death in 13 asbestos employees, whereas none of the controls died from this cause.

The observed numbers of cases of lung cancer (ICD 162, 7th revision) and cases of cancer of the digestive organs (ICD 150-159, 7th revision) in asbestos employees, together with controls, are listed in Table 3. The differences in lung cancer
TABLE 2

Number of Deaths by CAuse among Asbestos EMPLOYEES AND CONTROLS

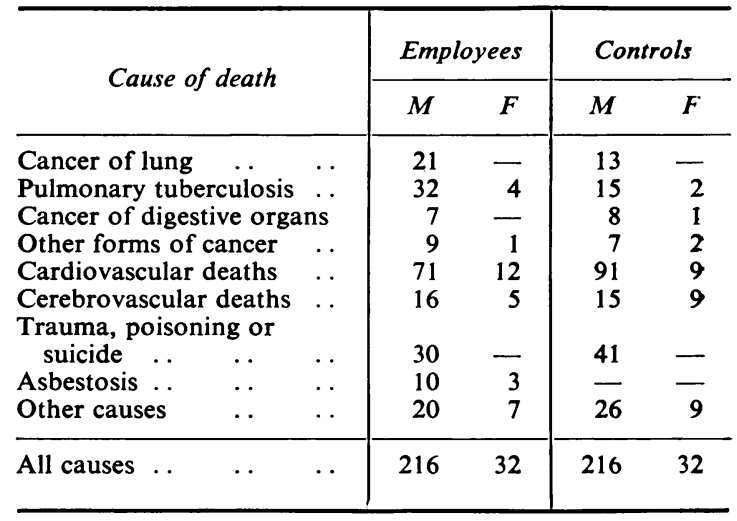

between the asbestos and control groups were not significant. Moreover, no excess risk of cancer was apparent in the digestive organs of asbestos employees, compared with either the controls or the expected figures derived from the national mortality data.

However, the proportional mortality study showed a significant $(P<0.05)$ excess of deaths for lung cancer in asbestos employees compared to the national figures. The most marked differences between the observed and expected numbers were in the age group 45-54 ( $P<0.01)$, and in cases with more than 10 years' exposure $(P<0.01$, Table 4$)$.

It has been shown that smoking cigarettes is a strong and common aetiological factor in lung cancer (Smoking and Health, 1964), and that asbestos workers tend to consume more cigarettes than a normal population (Selikoff, Hammond, and Churg, 1968). The estimation of smoking habits was

TABLE 3

Observed and Expected ${ }^{1}$ Numbers of Lung Cancer and Cancer of Digestive Organs in Deaths among Asbestos Employees and Controls, by Age

\begin{tabular}{|c|c|c|c|c|c|c|}
\hline \multirow{2}{*}{ Age } & \multicolumn{3}{|c|}{ Lung cancer } & \multicolumn{3}{|c|}{ Cancer of digestive organs } \\
\hline & Asbestos & Controls & Expected & Asbestos & Controls & Expected \\
\hline $15-24$ & - & - & 0.0 & - & - & 0.0 \\
\hline $25-34$ & - & - & 0.1 & - & - & 0.3 \\
\hline $35-44$ & 1 & - & 0.7 & 1 & - & 1.2 \\
\hline $45-54$ & 10 & 6 & 3.4 & 1 & 4 & 3.2 \\
\hline $55-64$ & 7 & 4 & 5.6 & 1 & 1 & 5.3 \\
\hline $65-74$ & 3 & 3 & $2 \cdot 6$ & 4 & 4 & $4 \cdot 2$ \\
\hline 75- & - & - & 0.2 & - & - & 0.7 \\
\hline All ages & 21 & 13 & 12.6 & 7 & 9 & 14.9 \\
\hline
\end{tabular}

${ }^{1}$ Assuming age-specific rates for deaths from lung cancer and cancers of digestive organs in Finland 1958. 
TABLE 4

ObSeRVed AND EXPECTED ${ }^{1}$ Numbers OF LUNG Cancer and of Cancer of Digestive Organs in Deaths among Asbestos Employees With MORE THAN 10 YEARS OF EXPOSURE, BY AGE

\begin{tabular}{c|cc|cc}
\hline \multirow{3}{*}{ Age } & \multicolumn{2}{|c|}{ Lung cancer } & \multicolumn{2}{c}{$\begin{array}{c}\text { Cancer of digestive } \\
\text { organs }\end{array}$} \\
\cline { 2 - 5 } & Observed & Expected & Observed & Expected \\
\hline $35-44$ & 1 & 0.0 & - & 0.0 \\
$45-54$ & 5 & 1.0 & 1 & 0.8 \\
$55-64$ & 2 & 1.0 & - & 0.8 \\
$65-74$ & - & 0.4 & 1 & 0.5 \\
\hline Total & 8 & 2.4 & 2 & 2.1 \\
\hline
\end{tabular}

${ }^{1}$ Assuming age-specific rates for deaths from lung cancer and cancer of digestive organs in Finland 1958

made with a view to avoiding confusion due to the effects of smoking upon lung cancer deaths.

The smoking habits of persons already dead were not known. However, results were available, based upon the postal questionnaire, for the smoking habits of existing employees and controls (Table 5). On the assumption that similar differences existed among the dead employees and controls, and that there was a linear relationship between the number of cigarettes smoked daily and the risk of lung cancer, the following are the relative risks (Kahn, 1966):

Number of cigarettes/day Risk

$\begin{array}{lr}\text { None } & 1 \\ \leqslant 15 & 10 \\ \geqslant 15 & 15\end{array}$

A relative risk of $7 \cdot 3$ of death from lung cancer will exist among the control population compared to a non-smoker, and a relative risk of 8.4 of death from lung cancer for asbestos workers.

The expected figures for lung cancer should be adjusted for smoking if it is assumed that the excess smoking among asbestos workers is independent of

TABLE 5

SMoking Habits of EMPloyees and Controls (by postal questionnaire)

\begin{tabular}{|c|c|c|c|c|}
\hline \multirow{2}{*}{$\begin{array}{c}\text { Cigarettes } \\
\text { smoked } \\
\text { daily }\end{array}$} & \multicolumn{2}{|c|}{ Employees } & \multicolumn{2}{|c|}{ Controis } \\
\hline & Number & $\%$ & Number & $\%$ \\
\hline $\begin{array}{l}\text { None } \\
\leqslant 15 \\
>15\end{array}$ & $\begin{array}{l}262 \\
300 \\
225\end{array}$ & $\begin{array}{l}33 \cdot 3 \\
38 \cdot 1 \\
28 \cdot 6\end{array}$ & $\begin{array}{l}314 \\
326 \\
147\end{array}$ & $\begin{array}{l}39.9 \\
41.4 \\
18.7\end{array}$ \\
\hline Total & 787 & $100 \cdot 0$ & 787 & $100 \cdot 0$ \\
\hline
\end{tabular}

the asbestos environment. Given the smoking habits of asbestos workers, the expected numbers of lung cancer cases due to smoking would be 15 for the total group of asbestos workers, and 3 for the group with more than 10 years' exposure. The difference is significant $(P<0.05)$ only for the observed and expected numbers of employees with more than 10 years' exposure.

With these assumptions taken as a basis, together with the multiplicativity of risk induced by cigarette smoking and asbestos exposure (Doll, 1971; Berry, Newhouse, and Turok, 1972), the relative risk, compared to a nonsmoker without exposure to asbestos, of lung cancer is:

Non-smoking asbestos worker

Smoker without asbestos exposure $1 \cdot 4$

Asbestos worker and smoker

Analysis of health condition and respiratory symptoms among employees of the asbestos company still living The employees of the asbestos mining company included a number of persons who cannot be regarded as true asbestos workers as they had never worked in the dusty environment of the open mines or the mill, or had worked for only a relatively short period in them. Consequently, a high-risk sub-group of living asbestos employees was selected. This subgroup, which comprised only those who had worked for 10 years or more either in the mines or in the mill, and had been heavily exposed to asbestos dust, was compared with controls matched by age and sex.

Three variables, state of health, cough, and dyspnoea, were analysed from the answers given in the postal questionnaire.

The different smoking habits of the asbestos employees and controls (Table 5) necessitated adjustment of the prevalence rates of respiratory symptoms and diseases according to the number of cigarettes smoked daily. The matched controls for both groups, the workers subjected to heavy exposure, and the other living employees displayed a systematic difference of prevalence rates. This is probably attributable to the higher mean age of the group with longer periods of exposure.

The entire group of living asbestos workers consisted of 787 cases; of these, 110 had been engaged in asbestos work, with heavy exposure, for 10 or more years.

\section{State of health}

Table 6 shows employees and controls, divided into sub-groups in accordance with their own evaluation of state of health. No effect of asbestos exposure upon the subjective state of health of either the asbestos workers as a whole or the sub-group heavily exposed was apparent. 
TABLE 6

Subjective State of Health of Asbestos EMPloyees aNd CoNTrols, aNd AsBestos EMPloyeEs With HeAVy EXPOSURE to AsBestos

\begin{tabular}{l|cc|cc}
\hline & \multicolumn{2}{|c|}{ All living } & \multicolumn{2}{c}{ Heavy exposure } \\
\cline { 2 - 5 } & Employees & Controls & Employees & Controls \\
\hline Healthy & 412 & 445 & 45 & 47 \\
$\begin{array}{l}\text { Not } \\
\quad \text { healthy }\end{array}$ & 375 & 342 & 65 & 63 \\
$\begin{array}{l}\text { Total } \\
\text { Tot }\end{array}$ & 787 & 787 & 110 & 110 \\
\hline
\end{tabular}

\section{Occurrence of cough}

A correlation was observed between cough and exposure to asbestos (Tables 7 and 8). The rates for all smoking categories were adjusted by the direct method to the distribution of smoking habits for all controls.

The prevalence of cough increased with exposure to asbestos and number of cigarettes smoked daily. But for the heavy exposure group an increase in the number of cigarettes smoked did not exert any effect upon the prevalence of cough. In the whole group of asbestos employees, the prevalence of a cough was twice (2.2) as common compared with the controls. Furthermore, in the heavy exposure group, the occurrence of cough was more than four times (4.4) as common as in their controls. The increased prevalence of cough among the exposed group was statistically significant $(99 \%$ confidence interval of the relative risk for the total group was from 1.7 to $3 \cdot 6$ ).

\section{Occurrence of dyspnoea}

Dyspnoea at rest, under light strain, and under considerable strain such as running was enquired for in the questionnaire. Only cases with dyspnoea at rest were accepted for the analysis. Dyspnoea was commoner among the asbestos workers than among
TABLE 8

Relative Rates for COUGH by Exposure to ASBestos aNd SMOKING Habits, COMPARED TO RATE FOR NON-EXPOSED CONTROLS WITH Same Smoking Habits as Exposed Employees

\begin{tabular}{c|ccc}
\hline \multirow{2}{*}{$\begin{array}{c}\text { Cigarettes } \\
\text { smoked } \\
\text { daily }\end{array}$} & \multicolumn{3}{|c}{ Exposure } \\
\cline { 2 - 4 } & Moderate & Heavy & Total \\
\hline None & 1.91 & 5.88 & 2.51 \\
$\leqslant 15$ & 1.81 & 4.24 & 2.42 \\
$>15$ & 1.46 & 2.97 & 1.75 \\
\hline Total, adj. & 1.73 & 4.38 & 2.25 \\
\hline
\end{tabular}

the controls, but no trend in the prevalence of dyspnoea with increased exposure to asbestos was apparent. The relative risk of dyspnoea slightly exceeded 3 both in the heavily exposed group and in the moderately exposed group ( $99 \%$ confidence limits being $2 \cdot 2$ and 4.9 for the total group).

The prevalence rates of dyspnoea in relation to smoking habits displayed a somewhat inconsistent pattern (Table 9). The prevalence was higher for asbestos workers than for the controls in every

\section{TABLE 9}

Prevalence (Per Cent) and Relative Risks of DyspNoea, by Smoking Habits, For ASBESTOS EMPLOYEES AND CONTROLS

\begin{tabular}{|c|c|c|c|}
\hline \multirow{2}{*}{$\begin{array}{l}\text { Cigarettes } \\
\text { smoked } \\
\text { daily }\end{array}$} & \multicolumn{3}{|c|}{ Prevalence rate } \\
\hline & Employees & Controls & Ratio \\
\hline $\begin{array}{l}\text { None } \\
\leqslant 15 \\
>15\end{array}$ & $\begin{array}{l}19.8 \\
23.0 \\
13.3\end{array}$ & $\begin{array}{l}3.8 \\
7 \cdot 7 \\
7 \cdot 5\end{array}$ & $\begin{array}{l}5.6 \\
3.0 \\
1.8\end{array}$ \\
\hline Total, adjusted ${ }^{1}$ & $19 \cdot 9$ & $6 \cdot 1$ & $3 \cdot 3$ \\
\hline
\end{tabular}

${ }^{1}$ Adjusted for smoking distribution of controls

TABLE 7

Prevalence (per cent) of Cough by Exposure to Asbestos, and Smoking Habits

\begin{tabular}{|c|c|c|c|c|c|c|}
\hline \multirow{3}{*}{$\begin{array}{c}\text { Cigarettes } \\
\text { smoked } \\
\text { daily }\end{array}$} & \multicolumn{6}{|c|}{ Exposure } \\
\hline & \multicolumn{2}{|c|}{ Moderate } & \multicolumn{2}{|c|}{ Heavy } & \multicolumn{2}{|c|}{ Total } \\
\hline & Employees & Controls & Employees & Controls & Employees & Controls \\
\hline $\begin{array}{l}\text { None } \\
\leq 15 \\
<15\end{array}$ & $\begin{array}{l}13 \cdot 9 \\
27 \cdot 3 \\
30 \cdot 2\end{array}$ & $\begin{array}{r}7 \cdot 3 \\
15 \cdot 1 \\
20 \cdot 6\end{array}$ & $\begin{array}{l}58 \cdot 8 \\
57 \cdot 4 \\
56 \cdot 5\end{array}$ & $\begin{array}{l}10 \cdot 0 \\
13 \cdot 6 \\
19 \cdot 0\end{array}$ & $\begin{array}{l}16 \cdot 8 \\
32 \cdot 0 \\
35 \cdot 6\end{array}$ & $\begin{array}{r}6 \cdot 7 \\
13 \cdot 2 \\
19 \cdot 7\end{array}$ \\
\hline Total, adj. ${ }^{1}$ & $22 \cdot 5$ & $13 \cdot 0$ & $57 \cdot 8$ & $13 \cdot 2$ & $26 \cdot 6$ & $11 \cdot 8$ \\
\hline
\end{tabular}

ISmoking distribution of controls as standard 
smoking category, even if the risk of dyspnoea did not continuously increase with an increasing number of cigarettes smoked.

\section{Discussion}

Of the 51 cases who could not be traced because of unknown address or non-response, despite the questionnaire being posted to them several times, only seven had been employed by the asbestos mining company for two years or more. Four of them had worked in either the mine or the mill. This gap in the material is small and does not materially affect the results, which are naturally much more dependent upon the reliability of the information compiled.

No mesotheliomas were found in this series, and the possibility that they are hidden among the cancer cases is small. Ten cases of malignancy other than lung cancer or cancer of the digestive organs were found: three of these were of prostatic cancer, one cancer of the lip, one of the bladder, one of the breast, one Hodgkin's disease, one laryngeal cancer, and one cancer of the thyroid gland. In one case the primary site was uncertain, but there were generalized metastases including bones; this is not typical of mesothelioma. Among cancers of the digestive organs, one was oesophageal, one colonic, one pancreatic, and the remainder were stomach cancers. It seems unlikely that any of these cases of malignancy could have been a mesothelioma.

Of the 36 cases of tuberculosis, 10 had been at work during the war years, 1940-44. All of them were young men who had worked for only a relatively short period and who died soon after leaving the work. In all probability they had been employed without any medical examination because of the shortage of manpower during the war.

The excess of tuberculosis among the asbestos group resulted in an excess of traumatic deaths in the control group. The matched controls for the seven young cases of tuberculosis who died during the war years 1939-45 included three young men killed in the war.

The 36 deaths from tuberculosis included 11 which took place during the war and six cases under 40 years of age; two cases confirmed at necropsy, seven cases confirmed radiologically and/or bacteriologically at a sanatorium, and 10 cases with incomplete evidence of the cause of death. Some of these 10 cases might possibly have been pleural mesothelioma or lung cancer.

In 13 cases, asbestosis was given as the primary cause of death on the death certificate, and it was mentioned as a co-factor in 22 cases. Of the 21 cases who had died of lung cancer, eight also had asbestosis; five were found at necropsy. Of the remaining 13 lung cancer cases, only one was found at necropsy but with no evidence of asbestosis. Of the 12 remaining cases of death from lung cancer, only four had been employed by the asbestos mining company for five years or more and of these three might have had some degree of asbestosis at death. From these figures the entire group of 21 lung cancer cases included a maximum of 11 cases with asbestosis and lung cancer combined.

In the whole series of 248 deaths of former employees of the asbestos mining company, 35 cases had asbestosis either as a primary cause of death or as a co-factor. It is possible that anthophyllite-asbestos and lung cancer are only weakly associated in Finland, since only eight (possibly 11) of the 35 asbestosis cases had lung cancer at the time of death. By comparison, Buchanan (1965) stated that in England half of those with asbestosis at death also suffered from lung cancer.

This study indicates an excess of lung cancer cases, probably attributable to asbestos exposure, but this excess is less than that reported in most other mortality studies of asbestos workers (König, 1960; Mancuso and Coulter, 1963; Selikoff et al., 1964; Buchanan, 1965; Doll, 1965; Enterline, 1965; Smither, 1965; Enterline and Kendrick, 1967; Elmes and Simpson, 1971). However, these reports on the carcinogenic effect of asbestos have been derived mainly from mortality data on employees in the asbestos textile trade, or insulation workers and pipe coverers in urban areas, with higher exposure to other carcinogenic factors (Wright, 1969).

Only three reports have been published on mortality among asbestos miners and millers. All of them are based on chrysotile asbestos (Braun and Truan, 1958; Kogan, Troitsky, and Gulevskaya, 1966; McDonald et al., 1971). McDonald has reported from Canada that among the $5 \%$ in the highest dust category, the age-standardized mortality rate was $20 \%$ higher than in the other groups with lower exposure. This excess was accounted for in equal proportions by respiratory, cardiovascular, and malignant diseases. The authors conclude that the true difference between maximally and minimally exposed mortality in lung cancer is about threefold. However, the overall risk of lung cancer among asbestos workers was not higher than that in the general population. The whole group of employees who had died included 100 cases of respiratory malignancy, with only three mesotheliomas.

In the present material for the heavily exposed group a similar difference is seen between the observed and expected numbers of cases of lung cancer (8 against 2.4). The present series included no mesotheliomas (or possibly one) as compared with three in the Canadian series. However, the number of deaths, 248 , is only $10 \%$ of those in the Canadian study. 
A Soviet investigation into asbestos mortality (Kogan et al., 1966) has shown an increased risk of lung cancer by a factor of 1.9 for miners, 3.1 for millers, and $\mathbf{2 \cdot 3}$ for factory workers, as compared with the general population. This is roughly comparable with the twofold risk (21/13) observed in the present study.

The combined effect of asbestos and smoking upon lung cancer has been estimated by Selikoff $e t$ al. (1968) among insulation workers and by Meurman et al. (1970) among lung cancer patients. The former authors reported a relative risk of 92 for an asbestos worker who smokes cigarettes compared with a nonexposed non-smoker. This is more than five times as great as the estimate of 17 from this study.

The present material does not provide any foundation for distinguishing whether the effect of smoking and asbestosis on the risk of lung cancer is multiplicative or additive. The estimate of risk due to asbestosis for the Finnish asbestos workers increased from 1.4 to 4.4 in terms of the unit risk for nonexposed non-smokers on the assumption of an additive rather than a multiplicative model. However, an increasing amount of evidence (Selikoff et al., 1968; Doll, 1971; Berry et al., 1972) favours the multiplicative hypothesis for the action of these two carcinogens.

The number of deaths taken as a basis for the results obtained is rather small; only 43 cases had been at work for 10 years or more and, of these, 34 cases had been actual miners or mill workers with heavy exposure to asbestos. Furthermore, only nine cases had been employed for 20 years or more. Six of them had asbestosis at death, and five of the nine died from lung cancer. Thus, even though one half of the workers with exposure lasting 20 years or more died from lung cancer, it is too early to draw any far-reaching conclusions on the association of malignancy and anthophyllite asbestos exposure in Finland.

The results given in the section concerned with living employees of the asbestos mining company indicate that the estimate of the general state of health of the cases and their controls is too subjective to permit of any reliable evaluation. A considerable number of cases who felt healthy simultaneously admitted a chronic cough or severe dyspnoea. Langlands, Wallace, and Simpson (1971) have concluded that the prevalence of radiographic abnormality of the lung fields or pleura increases from $13 \%$ in men exposed to asbestos for less than 10 years to $85 \%$ in men exposed for 30 years or more. Of 252 former asbestos workers, 140 were found to have pleural and/or pulmonary pathology in chest radiographs (Kiviluoto and Meurman, 1970).

A higher number of heavy smokers is likely to be found among asbestos workers than in a general population (Selikoff et al., 1968; Elmes and Simpson,
1971). In this study also asbestos workers smoked more commonly than did their controls living in the agricultural area. However, the prevalence of cough or dyspnoea among the asbestos workers is not completely attributable to the more prevalent smoking of cigarettes. Cough was more than twice as common among asbestos employees than among their controls, after adjustment for the effect of smoking. The increase in the prevalence of a cough in relation to the number of cigarettes smoked daily is steeper among controls than among asbestos workers. In employees with heavy asbestos exposure there was no trend of cough with number of cigarettes smoked. The results indicate that mild exposure to asbestos exerts an additive effect upon cough in different smoking categories, whereas the effect of heavy exposure to asbestos outweighs the effect of other factors (smoking). Dyspnoea is more than three times as common among asbestos workers as among their controls, after adjustment for smoking habits. It can be assumed that the excess of dyspnoea among asbestos workers is attributable to asbestos, and might indicate more or less advanced asbestosis. The somewhat inconsistent pattern of dyspnoea in relation to the smoking of cigarettes may be attributable to some of the interviewees having stopped smoking as a consequence of dyspnoea.

As the exposure is of relatively short duration, it is possible that the results obtained here underestimate the long-term effects of asbestos upon the morbidity of the population exposed.

The authors are indebted to Mrs. Tuula Tuunainen, who has collected the personal data and controls for the present study, and to Mr. Urpo Joutsenlahti, M.A., for assistance in data-processing the material. The study was supported by a grant from the International Agency for Research on Cancer.

\section{References}

Berry, G., Newhouse, M. L., and Turok, M. (1972). Combined effect of asbestos exposure and smoking on mortality from lung cancer in factory workers. Lancet, 2, 476-479.

Braun, D. C. and Truan, T. D. (1958). An epidemiological study of lung cancer in asbestos miners. Archives of Industrial Health, 17, 634-653.

Buchanan, W. D. (1965). Asbestosis and primary intrathoracic neoplasms. Annals of the New York Academy of Sciences, 132, 507-518.

Doll, R. (1965). Mortality from lung cancer in asbestos workers. British Journal of Industrial Medicine, 12, 81-86.

- (1971). The age distribution of cancer: Implications for models of carcinogenesis (with Discussion). Journal of the Royal Statistical Society, Series A, 134, 133-166.

- Muir, C., and Waterhouse, J. eds. (1970). Cancer Incidence in Five Continents, vol. 2, International Union against Cancer. Springer-Verlag, Heidelberg, Berlin, New York.

Elmes, P. C. and Simpson, M. J. C. (1971). Insulation workers in Belfast 3. Mortality 1940-1966. British Journal of Industrial Medicine, 28, 226-236.

Enterline, P. E. (1965). Mortality among asbestos products 
workers in the United States. Annals of the New York Academy of Sciences, 132, 156-165.

- and Kendrick, M. A. (1967). Asbestos-dust exposures at various levels and mortality. Archives of Environmental Health, 15, 181-186.

Gaze, R. (1965). The physical and molecular structure of asbestos. Annals of the New York Academy of Sciences, 132, 23-30.

Holt, P. F., Mills, J., and Young, D. K. (1965). Experimental asbestosis with four types of fibers. Importance of small particles. Annals of the New York Academy of Sciences, 132, 87-97.

Kahn, H. A. (1966). The Dorn study of smoking and mortality among U.S. Veterans: Report on eight and one-half years of observation. National Cancer Institute, Monograph No. 19, 1-126.

Kiviluoto, R. (1960). Pleural calcification as a roentgenologic sign of non-occupational endemic anthophyllite-asbestosis. Acta Radiologica, Suppl. 194, 1-67.

- , and Meurman, L. (1970). Results of asbestos exposure in Finland. In: Pneumoconiosis: Proceedings of the International Conference, Johannesburg 1969, pp. 190-191, edited by H. A. Shapiro. Oxford University Press, Cape Town.

Kogan, F. M., Troitsky, S. Y., and Gulevskaya, M. R. (1966). On the carcinogenic effect of asbestos dust. Gigiena $i$ Sanitariya, 31, No. 8, 28-33.

König, J. (1960). UUber die Asbestose. Archiv für Gewerbepathologie und Gewerbehygiene, 18, 159-204.

Langlands, J. H. M., Wallace, W. F. M., and Simpson, M. J. C. (1971). Insulation workers in Belfast 2. Morbidity in men still at work. British Journal of Industrial Medicine, 28, 217-225.

Mancuso, T. F. and Coulter, E. J. (1963). Methodology in industrial health studies. The cohort approach, with special reference to an asbestos company. Archives of Environmental Health, 6, 210-226.

McDonald, J. C., McDonald, A. D., Gibbs, G. W., Siemiatycki, J., and Rossiter, C. E. (1971). Mortality in the chrysotile asbestos mines and mills of Quebec. Archives of Environmental Health, 22, 677-686.

Meurman, L. (1966). Asbestos bodies and pleural plaques in a Finnish series of autopsy cases. Acta Pathologica et Microbiologica Scandinavica, Suppl. 181, 1-107.

, Hormia, M., Isomäki, M., and Sutinen, S. (1970).
Asbestos bodies in the lungs of a series of Finnish lung cancer patients. In Pneumoconiosis: Proceedings of the International Conference, Johannesburg 1969, pp. 404-407, edited by H. A. Shapiro. Oxford University Press, Cape Town.

Newhouse, M. L. (1970). The mortality of asbestos factory workers. In Pneumoconiosis: Proceedings of the International Conference, Johannesburg 1969, pp. 158-164, edited by H. A. Shapiro. Oxford University Press, Cape Town.

Pedersen, E., Magnus, K., Mork, T., Hougen, A., Bjelke, E., Hakama, M., and Saxén, E. (1969). Lung cancer in Finland and Norway-an epidemiological study. Acta Pathologica et Microbiologica Scandinavia, Suppl. 199, 1-74.

Raunio, V. (1966). Occurrence of unusual pleural calcification in Finland. Studies on atmospheric pollution caused by asbestos. Annales Medicinae Internae Fenniae, 55, Suppl. 47, 1-61.

Selikoff, I. J., Churg, J., and Hammond, E. C. (1964). Asbestos exposure and neoplasia. Journal of the American Medical Association, 188, 22-26.

- Hammond, E. C., and Churg, J. (1968). Asbestos exposure, smoking, and neoplasia. Journal of the American Medical Association, 204, 106-112.

Smither, W. J. (1965). Secular changes in asbestosis in an asbestos factory. Annals of the New York Academy of Sciences, 132, 166-181.

Smoking and Health (1964). Report of the Advisory Committee to the Surgeon General of the Public Health Service. Public Health Service Publication No. 1103, pp. 17-387. U.S. Department of Health, Education and Welfare, Washington DC, U.S.A.

Timbrell, V. (1970). Characteristics of the International Union against Cancer standard reference samples of asbestos. In: Pneumoconiosis: Proceedings of the International Conference, Johannesburg 1969, pp. 28-36, edited by H. A. Shapiro. Oxford University Press, Cape Town.

Wright, G. W. (1969). Asbestos and health in 1969. American Review of Respiratory Disease, 100, 467-479.

Received for publication 21 May 1973

Accepted for publication 17 August 1973 